\title{
THE LONG-TERM EFFECTS OF WIDE LAMINECTOMY FOR LUMBAR DISC EXCISION
}

\author{
A Review of 130 Patients
}

\author{
R. K. JACKSON, LONDON, EnGLAND \\ From St Thomas's Hospital, London
}

It is thirty-seven years since Mixter and Barr (1934) presented their classical paper on the surgical treatment of ruptured intervertebral discs. In 1941 they published the short-term results in ninety-four patients with lumbar lesions. They showed that fusion of the spine at the time of laminectomy lowered the incidence of subsequent back symptoms and concluded that laminectomy weakened the back.

The first long-term results of lumbar disc operation did not appear until after the second world war. In 1949 Spurling and Grantham reported a questionnaire follow-up of 327 patients after simple disc clearance through a unilateral interlaminar approach. In $19510^{\circ}$ Connell published a series of 500 interlaminar operations followed up for two to ten years and in the same year Burns and Young published a review of 616 patients followed up for a similar period after wide laminectomy. The initial sciatica was relieved in much the same proportion in all three series. Post-operative back pain and recurrent sciatica were examined in detail both by Spurling and Grantham and by $\mathrm{O}^{\circ}$ Connell. Burns and Young, though stating that the large proportion of cures in their series indicated that the spine was not weakened by the operation, did not investigate the incidence of back pain after laminectomy.

No one has seriously challenged the assumption by Barr and Mixter (1941) that compared with the interlaminar approach the better exposure afforded by wide laminectomy is offset by greater post-operative disability. This "disability" has never been properly determined. The object of the present review was to investigate more fully the long-term effects of wide laminectomy and to compare the morbidity after this operation with that of the interlaminar approach.

\section{MATERIAL}

One hundred and thirty patients operated on at St Thomas's Hospital between 1958 and 1967 have been reviewed. All the operations were carried out by the technique described by Burns and Young. The lowest lumbar spinous process and the medial halves of both laminae were excised together with the ligamentum flavum above and below. Muscle was stripped laterally as far as the facets but the posterior articulations were not disturbed. After retraction of the dura the lowest two lumbar disc spaces were routinely inspected. Bilateral clearance of the defective disc, or discs, was carried out. No special post-operative measures were taken and patients were allowed up between ten days and three weeks after operation.

In five patients no disc lesion was found. Of the remaining 125 patients with proven disc lesions, 70 per cent were male and 30 per cent female. Operation was most common in the fourth decade in both sexes (Fig. 1). Forty per cent were employed in heavy work and the remainder in light manual, clerical or domestic work. There was an associated psychiatric history in fourteen patients (10 per cent), three of whom had negative explorations.

All patients had plain radiographs of the lumbar spine before operation. The incidence of sacralisation of the fifth lumbar vertebra was 5 per cent. Myelography was carried out only when there was clinical doubt about the level of the lesion or before re-exploration. The accuracy of myelographic localisation was 70 per cent.

At operation all but one of the lesions were in the lowest two lumbar discs. Protrusion or sequestration of the lumbo-sacral disc was found in 46 per cent and of the disc above in 
41 per cent of operations. A lesion of both discs was found in 12 per cent and in one patient an isolated protrusion of the third lumbar disc was found.

There were two acute cauda equina lesions due to large central protrusions of the fourth lumbar disc, both in males and both following manipulation of the back.

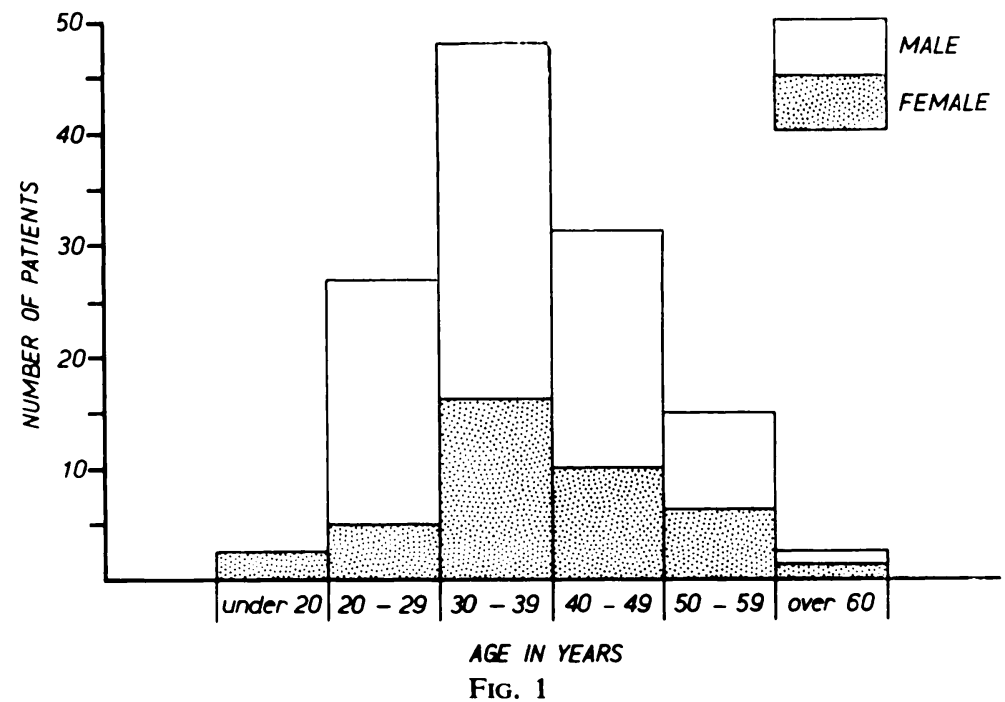

Age and sex distribution.

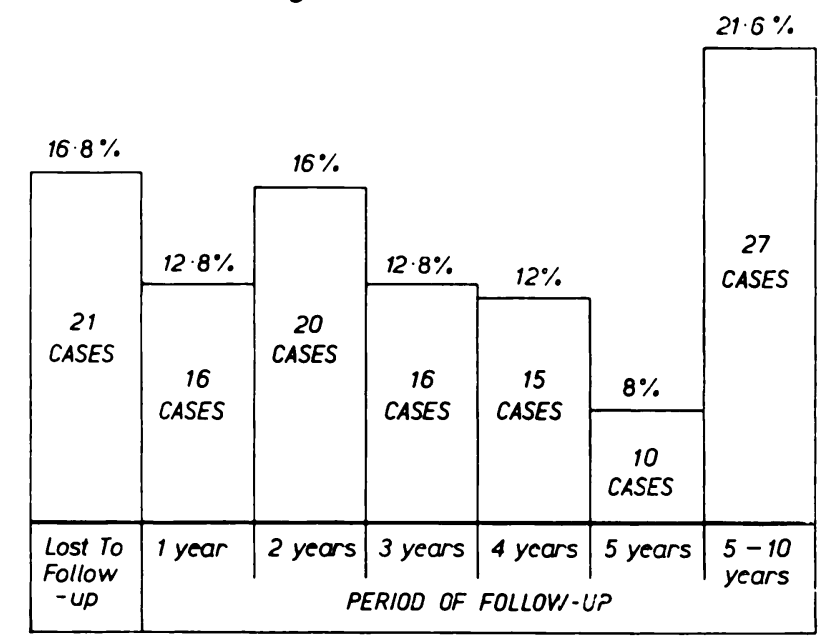

Fig. 2

Histogram showing period of follow-up.

Twenty-one patients could not be traced. The remaining 104 were personally examined and form the basis of this review. Residual symptoms and physical signs were noted and plain radiographs were obtained. In a smaller group of patients, some with and some without back pain, lateral radiographs of the lumbar spine were also taken in full flexion and full extension and the range of movement at the individual intervertebral spaces was measured by the technique of Begg and Falconer (1949).

\section{RESULTS}

IMMEDIATE POST-OPERATIVE COMPLICATIONS

Four per cent of the patients suffered transient back pain on mobilisation; 4 per cent had retention of urine requiring temporary catheterisation; and 3 per cent had a wound haematoma 
which resolved spontaneously. There was one meningocele which was subsequently repaired, and one frank wound infection. One patient developed venous thrombosis in the calf. There was no case of embolism and no death.

FOLLOW-UP

One hundred and four patients were examined between one and ten years after operation; the follow-up period was distributed as shown in Figure 2.

Subjective results-These were assessed in the four categories defined by O'Connell: 46 per cent were entirely symptom-free, 37.5 per cent were much improved with backache only after strenuous activity, 10.6 per cent had persistent or recurring back pain or sciatica but less than before operation, and $5 \cdot 7$ per cent were not improved by the operation.

Work capacity-Forty per cent were originally employed in heavy work and only 60 per cent of these were able to return to their work after operation; of the remainder, 92 per cent returned to their former jobs. The overall working capacity was 82 per cent.

Persistent sciatica-Seventeen per cent complained of persistent sciatica. This was mainly slight or occasional pain in the leg, but in three patients it was severe enough to require further exploration. In the first, there was an overlooked protrusion at an adjacent disc space; in the second, posterior nerve root adhesions were found; and in the third, the re-exploration failed to reveal a cause for the sciatica.

TABLE I

Relationship of Age to Incidence of Back Pain AFTER LAMINECTOMY

\begin{tabular}{|c|c|}
\hline $\begin{array}{c}\text { Age at time of } \\
\text { operation } \\
\text { (years) }\end{array}$ & $\begin{array}{c}\text { Incidence of back pain } \\
\text { after operation } \\
\text { (per cent) }\end{array}$ \\
\hline under 30 & 37 \\
\hline $30-39$ & 42 \\
\hline $40-49$ & 50 \\
\hline over 50 & 56 \\
\hline
\end{tabular}

TABLE II

Duration of Pre-operative Symptoms and InCidence of Back Pain after Laminectomy

\begin{tabular}{|l|c|}
\hline $\begin{array}{c}\text { Duration of } \\
\text { pre-operative symptoms }\end{array}$ & $\begin{array}{c}\text { Incidence of back pain } \\
\text { after operation } \\
\text { (per cent) }\end{array}$ \\
\hline Less than 6 months & 30 \\
\hline 6 months to 1 year & 44 \\
\hline 1 to 5 years . & 45 \\
\hline Over 5 years. & 61 \\
\hline
\end{tabular}

Recurrent sciatica-True recurrence after a pain-free interlude occurred in six cases $(5.7 \mathrm{per}$ cent); in all the spine was re-explored. Further protrusion or sequestration at the space which had previously been "cleared" was found in five of these recurrences. There was only one instance of an entirely new protrusion. All patients were cured by the second operation.

Back pain-The incidence of back pain in this review was 47 per cent. This was mainly discomfort after exertion, but in 15 per cent it was severe enough to preclude return to work or interfere with everyday activities.

The relationship of low back pain to other factors was of interest. The incidence increased with the age of the patient at the time of operation (Table I) and it was also directly related to the duration of symptoms before operation (Table II). The length of follow-up was not initially significant. After five years, however, there was an increasing incidence of back pain which was independent of age but which was closely paralleled by an increasing incidence of disc space narrowing (Fig. 3). There was a significantly greater incidence of back pain among heavy workers after correction for age, duration of symptoms and length of follow-up (Table III).

The overall incidence of back pain was unrelated to the presence of persistent or recurrent sciatica, although the pain was more likely to be severe in the group with persistent sciatica.

VOL. 53 B, NO. 4, NOVEMBER 1971 
Objective findings--Loss of the normal lumbar curve was nearly always persistent. Normal lumbar flexion was restored in 50 per cent of patients at the expense of a compensatory increase in movement in the upper lumbar segment, and 50 per cent had permanent restriction of movement. Local tenderness and tension signs disappeared except in patients with persistent

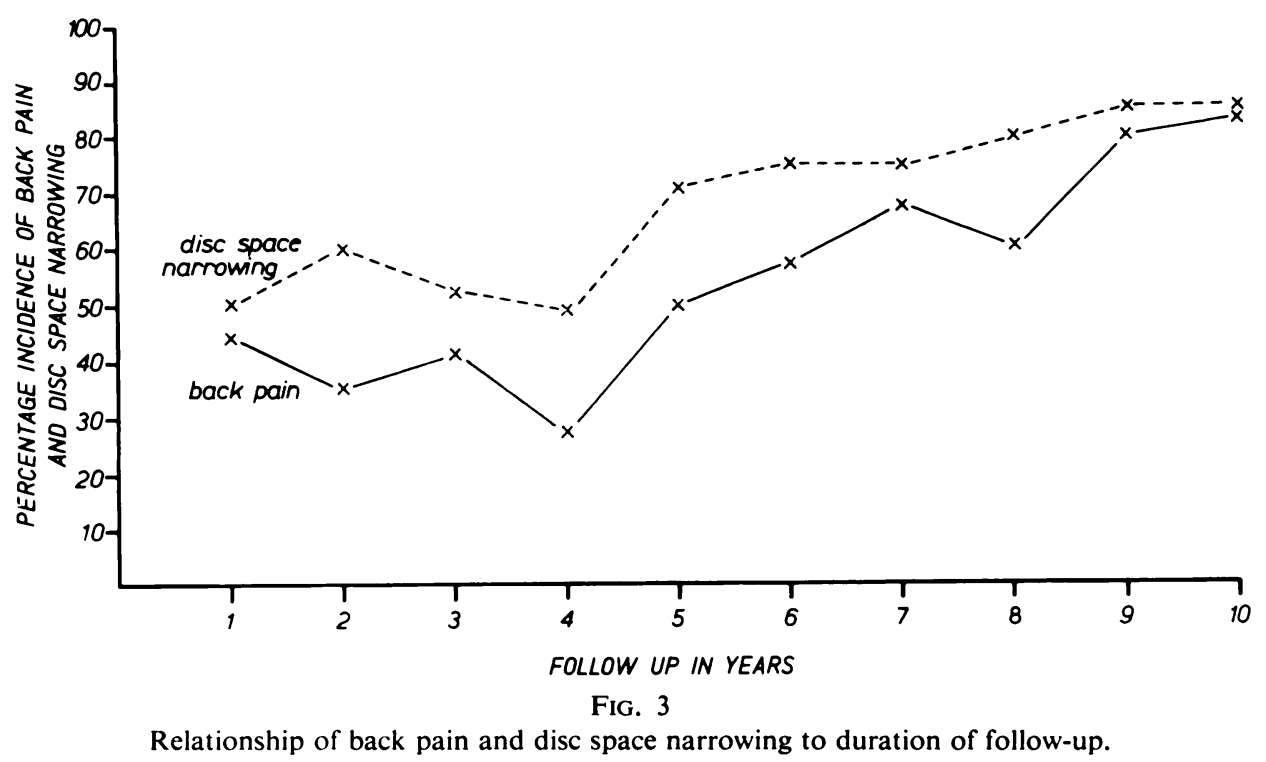

or recurrent sciatica. Objective sensory changes persisted as often as they recovered, whereas muscle weakness usually recovered. Absence of the ankle jerk, on the other hand, was usually persistent.

Radiographic findings. Disc space narrowing - Narrowing of the disc space did not invariably follow disc excision; indeed it was seen in no more than half of the patients in this review. Although the incidence rose with the age of the patient and with the length of follow-up, it was seen four times more often at those disc spaces which had been cleared surgically than at the adjacent spaces. There was no constant relationship between disc space narrowing and back pain; it was seen in 60 per cent of patients with pain and 50 per cent of those without.

TABLE III

RELATIONSHiP OF OCCUPATION TO INCIDENCE OF Back Pain after Laminectomy

\begin{tabular}{|l|c|}
\hline Type of work & $\begin{array}{c}\text { Incidence of back pain } \\
\text { after operation } \\
\text { (per cent) }\end{array}$ \\
\hline Heavy manual & 54 \\
\hline All others & $\cdot$ \\
\hline
\end{tabular}

Osteoarthritis of the posterior joints-The incidence of this radiographic finding was $6 \cdot 7$ per cent. It was found only in patients over forty-five. It was unrelated to the duration of preoperative symptoms or the length of follow-up and it was not necessarily accompanied by disc space narrowing. All but one of these patients had back pain on exertion and a characteristically stiff lumbar spine. They were all relieved by wearing a lumbar support. Motion studies-Using the method described by Begg and Falconer, the range of flexion and extension at each intervertebral space was studied in fifteen patients with back pain and 
fifteen patients without back pain. The total range of lumbar movement measured on the flexion and extension radiographs agreed with the observed clinical range in all cases. Limitation of movement at individual levels generally accompanied narrowing of disc spaces. Limitation of movement in the lower lumbar segment was often accompanied by compensatory increase of movement in the upper segment; again this was usually evident on careful clinical examination. An increase in range was seen occasionally at one disc space alone after excision of that disc but was not necessarily accompanied by pain and was not considered to be a sign of "instability". Marked limitation of total range was rarely seen except in the presence of osteoarthritis of the facet joints. No other abnormality in the pattern of lumbar movement was seen.

Spinal fusion-No fusion was done at the time of the laminectomy, but subsequent posterior fusion was carried out in six patients within two years of the original operation. All had severe and persistent back pain and four had an associated psychiatric illness. Only one patient returned to his former employment after operation. Apart from narrowing of the previously cleared disc space in half the cases there were no remarkable radiographic features.

\section{DISCUSSION}

The distribution of age and sex and the proportion of those employed in heavy work was similar in this series to those in previous reviews. The lumbo-sacral disc was involved slightly more often than the disc above, confirming the observations of most other authors. Although the number of double lesions recorded in the literature has increased since the recognition of the "concealed" disc (Dandy 1941), the incidence of 12 per cent in this series was not exceptional. The incidence of negative explorations was roughly the same as that found by Spurling and by O'Connell; but the association of psychiatric illness in three of the five patients in this review suggested that operative treatment should be considered with greater circumspection than usual in the presence of such a history.

It is generally agreed that plain radiographs should be taken before disc surgery in order to exclude other lesions and to take note of anatomical anomalies in the lumbar spine; any positive value is debatable. Myelography was considered to be a valuable localising measure by Spurling and Grantham (1949), Davis, Martin and Goldstein (1952), Decker and Shapiro (1957). O'Connell, on the other hand, used it only as a diagnostic procedure in "atypical cases". In the present review it was used when there was clinical doubt about the level of the lesion, but even then it was not entirely reliable and greater reliance was placed upon operative exploration.

The indications for operation were standard. Two operations were done as emergency procedures for the relief of bladder paralysis after manipulative treatment of the disc lesion. Both patients regained bladder function as a result of prompt recognition and operation, but these cases highlighted the danger of manipulation of the back, unless it is carried out in a place where facilities for emergency disc surgery are available.

Although the total subjective improvement and ability to return to work determine a patient's own assessment of the operation, the fact remains that relief of sciatica is the primary objective of the operation. In this series 83 per cent were completely relieved of the sciatica and in 5.7 per cent it was not improved at all. $\mathrm{O}^{\circ}$ Connell found 77.6 per cent completely cured of the original sciatica and only 0.7 per cent unrelieved by the operation. Spurling and Grantham, and Burns and Young, found that a smaller proportion were completely pain-free but their failure rate was similar to the figure in the present review (Table IV). When back symptoms were included the total subjective assessment was fairly constant in all four reviews. Working capacity was also fairly constant; it varied from 82 per cent in the present series to 92 per cent in $\mathrm{O}^{\prime}$ Connell's review and presumably reflected the constant ratio of light to heavy work rather than differences in operative technique.

VOL. 53 B, NO. 4, NOVEMBer 1971 
TABLE IV

Comparative Study of Subjective Assessment in This Review and in Three Other Long-term Reviews

\begin{tabular}{|c|c|c|c|c|}
\hline & \multicolumn{2}{|c|}{$\begin{array}{c}\text { Interlaminar exposure } \\
\text { (per cent) }\end{array}$} & \multicolumn{2}{|c|}{$\begin{array}{l}\text { Wide laminectomy } \\
\text { (per cent) }\end{array}$} \\
\hline & $\begin{array}{c}\text { Spurling and } \\
\text { Grantham (1949) }\end{array}$ & $\begin{array}{l}\text { O'Connell } \\
\text { (1951) }\end{array}$ & $\begin{array}{l}\text { Burns and } \\
\text { Young (1951) }\end{array}$ & Present review \\
\hline Complete relief of sciatica & 46 & $77 \cdot 6$ & 71 & 83 \\
\hline Failure to relieve sciatica & $8 \cdot 3$ & $0 \cdot 7$ & 7 & $5 \cdot 7$ \\
\hline Post-operative back pain & 60 & 40 & Not stated & 47 \\
\hline Total subjective cure . & 40 & 60 & 56 & 46 \\
\hline
\end{tabular}

Failure to cure the original sciatica is an immediate and obvious failure of the operation. Recurrent sciatica after a symptom-free interval is also a cause for dissatisfaction, particularly when the recurrence is found at the disc space which had previously been cleared. Spurling and Grantham re-explored $5 \cdot 5$ per cent of their cases for recurrent sciatica, O'Connell $2 \cdot 3$ per cent and Burns and Young 3 per cent. In the present series $5 \cdot 7$ per cent were re-explored and the findings confirmed the observations of Spurling and Grantham and of O'Connell that recurrence at the original site was four to five times commoner than a new protrusion at a previously unexplored disc. The implication of this consistent observation is that the original disc clearance was inadequate; but why? The overall incidence of recurrence was no less with the wide exposure, so that better access and bilateral clearance made no difference. It seems likely that incomplete degeneration of the disc, as Burns and Young have suggested, is responsible for the incomplete clearance at the original operation. O'Connell's assertion that bilateral exploration and clearance should be done only when the symptoms are bilateral is probably justified.

Burns and Young did not record the incidence of post-operative back pain in their paper, but the figure of 47 per cent in the present review compares favourably with the incidence of 60 per cent in Spurling's and 40 per cent in O'Connell's series of interlaminar operations. This suggests that wide laminectomy in itself is not a cause of backache. Although Burns and Young stated that "age and duration of symptoms did not affect prognosis", the incidence of back pain in this review did increase with the age of the patient and with the duration of symptoms before operation. The additional finding that the increasing frequency of back pain in those patients followed up for more than five years was paralleled by an increasing incidence of radiological disc space narrowing lent further support to the impression that backache is a feature of the underlying disc degeneration rather than the incidental operation to relieve sciatica.

Notwithstanding the increasing incidence of disc space narrowing in patients followed up for longer than five years, there was no constant relationship between this radiographic finding and the presence of back pain; moreover, only half the patients who subsequently required fusion had narrowed discs. It was therefore felt to have limited clinical significance, and I agree with Froning and Frohman (1968) that by itself it cannot be considered a reliable indicator for spinal fusion. Information in the literature concerning osteoarthritis of the posterior joints is scarce. In this review it was uncommon, confined to patients over forty-five and almost invariably associated with persistent back pain which was controlled by wearing a lumbar corset. None of these patients required spinal fusion.

Begg and Falconer showed that there is a normal pattern of movement at each lumbar segment which can be altered by disc degeneration and to a lesser extent by age. They found that an abnormal pattern before operation often returned to normal after excision of the 
affected disc, so that motion studies after operation were of less value than those taken before. Froning and Frohman (1968) also studied the changes in this pattern after laminectomy in fifty-two patients. They demonstrated restriction of flexion and extension in most patients who had had a successful laminectomy, but persistent mobility in patients with poor results. These findings were not confirmed in the present review. In addition motion radiographs taken after operation failed to provide any information that could not be learned from clinical examination and plain radiography of the lumbar spine.

There was no primary fusion in this series, but subsequent posterior fusion was carried out in six patients. Neither Spurling and Grantham, O'Connell or Burns and Young combined fusion with disc excision. On the other hand, Barr (1947), Howorth (1964) and others have advocated routine fusion at the time of disc removal. This practice obviously reduces the frequency of back pain after operation, as the results of these authors testify, but the routine addition of a procedure which adds significantly to the period of immobilisation does not seem to be justified when only half of these patients experience any back pain at all and no more than 6 per cent in fact will be sufficiently disabled to need further operation.

If there were some symptom or sign, or even operative finding, which would provide reliable indication there might then be a place for selective primary fusion. Hoover (1968), on the basis of his experience at the Mayo Clinic, concluded that fusion in conjunction with disc removal was indicated when residual or recurrent lumbar pain could reasonably be anticipated. Although patients were selected on the basis of their history, physical examination and radiographic findings, he admitted that it was difficult to obtain a consensus regarding positive indications. It need hardly be said that in the presence of spondylolisthesis or when the posterior articular facets have been damaged there is a clear indication for fusion, but apart from these no reliable indications for primary fusion were apparent in the present series.

This review was undertaken to analyse the results of disc excision using a wide laminectomy. The analysis was comparable to that used in the major reviews of the interlaminar operation and indicated that there was no significant difference in either the immediate or the long-term results of the two approaches. Although recognition of the lesion and clearance of the disc space is no more effective with wide laminectomy, the greater morbidity which its critics have claimed is not borne out by this study.

It seems fair to say therefore that the surgeon has a choice of operative approach before him which will be dictated largely by his experience, and it is not surprising to find that many advocates of the interlaminar approach in fact have developed their technique by gradually cutting down the extent of an originally wide exposure.

\section{SUMMARY}

1. The results of wide laminectomy of the fifth lumbar vertebra and disc excision in 132 patients are reviewed and compared with some published results of the interlaminar operation.

2. There was no significant difference in either the immediate or the long-term results of the two operations suggesting that post-operative morbidity was not related to operative technique. 3. The incidence of post-operative back pain was found to increase with age at operation, duration of pre-operative symptoms and length of follow-up, and supported the impression that backache is predominantly a feature of the underlying degenerative process rather than the incidental operation.

4. The significance of recurrent disc lesions is discussed. Recurrence usually occurred at the previously cleared disc space and was thought to indicate incomplete degeneration of the disc at the time of the original operation.

5. The place of fusion combined with disc excision is discussed. No reliable indications for coincident fusion were found in this series.

VOL. 53 B, NO. 4, NOVEMBER 1971 
6. The value of radiography is discussed. Plain radiographs were essential before operation to exclude other causes of backache and sciatica; otherwise they were of little value. Motion radiographs were no more helpful and myelography was used only when the level of the lesion was in doubt.

7. The risk of an acute cauda equina lesion following manipulation of a prolapsed lumbar disc is noted and the danger of manipulation, unless facilities for emergency surgery are available, is stressed.

I wish to thank Mr R. J. Furlong and Mr D. R. Urquhart for allowing me to review their patients and for their encouragement with this study.

\section{REFERENCES}

Barr, J. S. (1947): Ruptured Intervertebral Disc and Sciatic Pain. Journal of Bone and Joint Surgery, 29, 429.

BARR, J. S., and Mixter, W. J. (1941): Posterior Protrusion of the Lumbar Intervertebral Discs. Journal of Bone and Joint Surgery, 23, 444.

BegG, A. C., and FAlCONER, M. A. (1949): Plain Radiography in Intraspinal Protrusion of Lumbar Intervertebral Disks: A Correlation with Operative Findings. British Journal of Surgery, 36, 225.

Burns, B. H., and Young, R. H. (1951): Results of Surgery in Sciatica and Low Back Pain. Lancet, i, 245.

DANDY, W. E. (1941): Concealed Ruptured Intervertebral Disks. Journal of the American Medical Association, $117,821$.

Davis, L., Martin, J., and Goldstein, S. L. (1952): Sensory Changes with Herniated Nucleus Pulposus. Journal of Neurosurgery, 9, 133.

Decker, H. G., and Shapiro, S. W. (1957): Herniated Lumbar Intervertebral Disks. Archives of Surgery, $75,77$.

Froning, E. C., and Frohman, B. (1968): Motion of the Lumbosacral Spine after Laminectomy and Spine Fusion. Journal of Bone and Joint Surgery, 50-A, 897.

Hoover, N. W. (1968): Indications for Fusion at Time of Removal of Intervertebral Disc. Journal of Bone and Joint Surgery, 50-A, 189.

HoworTH, M. B. (1964): Low Backache and Sciatica: Results of Surgical Treatment. Journal of Bone and Joint Surgery, 46-A, 1485

Mixter, W. J., and BarR, J. S. (1934): Rupture of the Intervertebral Disc with Involvement of the Spinal Canal. New England Journal of Medicine, 211, 210.

O’Connell, J. E. A. (1951): Protrusions of the Lumbar Intervertebral Discs. Journal of Bone and Joint Surgery, 33-B, 8.

Spurling, R. G., and Grantham, E. G. (1949): The End-results of Surgery for Ruptured Lumbar Intervertebral Discs. Journal of Neurosurgery, 6, 57.

Stinchfield, F. E., and Cruess, R. L. (1961): Indications for Spine Fusion in Conjunction with Removal of Herniated Nucleus Pulposus. Instructional Course Lectures; the American Academy of Orthopaedic Surgeons, 18,41 . 